\title{
Benefit-sharing: an inquiry regarding the meaning and limits of the concept in human genetic research
}

\section{KADRI SIMM}

\begin{abstract}
The Human Genome Project and the related research and development activities have raised heated discussions around some very basic ethical and social issues. A much debated concern is that of justice in human genetic research and in possible applications, especially pertaining to questions of just benefit-sharing - who and based on what sort of argumentation has the right to require benefits arising from research and discoveries, and what can even be considered as benefits? In what follows I will be examining and clarifying the notion of benefit-sharing by focusing on its justifications. I will argue for certain qualifications and limitations in using this concept in specific and universal contexts.
\end{abstract}

\section{The idea of benefit-sharing}

Social justice has been first and foremost discussed as distributive justice or the sharing of benefits and burdens of social cooperation. Some objects of distribution (goods, services, duties) aspire to universal status, some are particular to a specific cultural, geographic, religious or other context, ultimately leaving the society or community handling the distribution as the measure by which certain goods become valued. It has generally been agreed that some goods or benefits like food and shelter are valued in all societies but the list is almost endless, including rights and liberties, money and commodities, jobs and opportunities, medical care, education, honours and prizes, personal security, special privileges, resources and so on.

How does research in human genetics link up with the discussions of benefit-sharing and justice? It has been suggested that the potential harm of the genetic revolution may rather lie in the ability of technology to distribute the available resources even more unequally than is currently the case, and in that way enforce and strengthen the existing disparities and inequity. ${ }^{1}$ On the other hand it is suggested that genetics might have enormous potential in levelling the existing inequalities and providing for a more just and equitable existence. Few would dispute that the impact the application of genetics might have in specific societies, as well as in a global context, owes much to the way its fruits, as well as its burdens, will be distributed. Hence the rise of the benefit-sharing concept, as most would agree that the potential for both greater good and greater harm is there.

There are also views that dispute the application of a benefit-sharing framework within genetics, and these are mostly related to a perception that discussions of benefit-sharing actually legitimate the attempts to commercialize and profit from (human) genome. This approach could be based on an understanding that genetic research is part of a larger humanistic project of medicine, where financial or other incentives should recede before important values like human health and quality of life. If human genetic research is about locating genes, understanding their functions and 
possibly attempting to modify these with the aim of treating or preventing the occurrence of the gene-related disease, ${ }^{2}$ it might seem curious why there are such heated debates on benefit-sharing. ${ }^{3}$ After all, so far, the understanding has been that the results of scientific inquiries suffice as the benefits are then available to the public. What has become of the concept of altruism in medical research? Why shouldn't we nowadays continue this honourable tradition of volunteering to help science to progress, so that future generations may have a life of less pain and illness? Indeed, some might feel offended when their honest altruistic participation is answered with the promise of a benefit. "That it not why I am doing it", people would say.

I think we can distinguish several counterarguments against this reasoning. Firstly, discussions of benefit-sharing are necessary even if one disagrees with the underlying trends of commercialising the genome, as closing ones eyes to a certain existing and increasingly powerful "evil" does not make it disappear. Also, non-engagement with the issue is an option that only some can afford, and not so for populations or communities already in the midst of genetic mining. Thirdly, we should also consider seriously the possibility that medical research itself has changed considerably and is consequently not an arena of altruism it perhaps used to be.

\section{Defining benefits or sharing what, exactly?}

Benefit-sharing is not a concept that has been invented for the explicit use in human genetic research (or genetics) and the origins of the discussion can be traced in various international documents:

- UN International Convention on Economic, Social and Cultural Rights (Article 15,1b): "The States Parties to the present Covenant recognize the right of everyone to enjoy the benefits of scientific progress and its applications";

- UN Convention on Biological Diversity (Article 17,7): "Each Contracting Party shall take legislative, administrative or policy measures /.../ with the aim of sharing in a fair and equitable way the results of research and development and the benefits arising from the commercial and other utilization of genetic resources /....";

- UNESCO Declaration on the Human Genome (Article 12a): "Benefits from advances in biology, genetics and medicine, concerning the human genome, shall be made available to all, with due regard for the dignity and human rights of each individual"; (Article 19a,iii): "In the framework of international co-operation with developing countries, States should seek to encourage measures enabling: countries to benefit from the achievements of scientific and technological research so that their use in favour of economic and social progress can be to the benefit of all".

The HUGO ethics committee expressed in its statement on benefit-sharing the following: "A benefit is a good that contributes to the well-being of an individual and/or a given community (e.g. by region, tribe, disease-group...). Benefits transcend avoidance of harm (non-maleficence) in so far as they promote the welfare of an 
individual and/or of a community. Thus, a benefit is not identical with profit in the monetary or economic sense. Determining a benefit depends on needs, values, priorities and cultural expectations." Firstly, benefit is clearly a positive change for the recipient(s) and should not be defined as simply providing a neutral result, with the insistence that potential burden was avoided. Secondly, and more importantly, the definition recognizes that benefits or goods cannot be established as neutral or objective facts but are inherently value-laden.

This is to say that behind the possibilities that are suggested as benefits (or burdens), lay understandings about why these things would be beneficial (or burdensome). And they are beneficial of course because they are valued as such, accepted by specific people, communities, societies. There are values that are shared by many, and then there are ones that test the limits of cultural relativism. All decisions, principles, perspectives within assessing the benefits and burdens are dependent on where one is looking from, and the values and benefit-sharing principles themselves can be traced to various understandings of justice - be it liberal, communitarian, utilitarian, egalitarian, libertarian etc. These perceptions include both political bias and moral judgement, and thus even the most general benefit-for-all is essentially value-based (as it values giving the benefit to all, and not only to the needy, for example).

The rhetoric, the media hype, the trusted position of scientists and researchers construct an arrangement that values and disvalues certain aspects of social life. Probably the most popular and popularised example of a benefit arising from human genetic research concerns health, be it individual (personalised medicine, pharmacogenomics) or public health related (preventive medicine, genetic screenings of embryos etc). Health is seemingly a non-controversial good that we all would be happy to have, or at least to improve on. Thus, generally speaking, within genetic research it is assumed that health is one such benefit accepted by certain, or even most, societies. But how are we then to assess the case from Finland where 10\% of the young men attending their compulsory national service were found to have problematic dental health (large number of cavities)? ${ }^{4}$ This is in a country where free dental care had been available to all and I do not believe we are dealing with extreme forms of cultural specificity, as Finland surely qualifies as a democratic country, with general values at least shared with other Western countries.

It has been argued, that "the choice of risks and the choice of how we live are taken together", 5 and I believe the same is true of hoped-for benefits. Similarly to the ways people choose to selectively pay attention to risks, they are also selective in defining benefits. Perhaps not surprisingly, those with dental problems came from the lower socio-economic strata of the society, and researchers attributed their disregard towards dental care to the values and lack of motivation of their strata. There is of course the slogan of "educating" them to the benefits of good dental health, but at the same time it is obvious that the problem was really not in education but rather, in the fact that they did not value free dental care enough to take advantage of it. ${ }^{6}$ Thus in our assessment of potential benefits and burdens, it is essential to realize that these conceptions are not a matter of education, as if the providing of "sufficient" information would guarantee the commonality of argument and perception. I think this sort of cautious attitude is especially important to keep in mind as regards the many potential "genetic" products that have been speculated about in the media, 
especially pertaining to different lifestyle, feel-good-smart-beautiful drugs and therapies.

The discussion above is not meant to attack genetics as irrelevant or unable to provide "real" benefits, but it does point to an important detail that should be accounted for in the benefit-sharing discussion. The example above also points to an important conclusion that $90 \%$ of the Finnish population do value dental health and thus insists that values, while different, can still be and are shared. The difficult aim of the just benefit-sharing would then be to take into account the diversity without ignoring the shared values. Secondly, careful attention needs to be paid to the question of who is defining and deciding upon specific benefits to be shared, but this is a point I will be unable to elaborate on presently.

Benefits put forward by the scientists, as well as the pharma industry, patients, investors and public health officials span a wide array of potential valued "goods", starting from improved health and scientific knowledge to financial gains and wider social benefits. What is behind the notions of benefits of genetic research that are utilized in various discussions? The HUGO definition is rather vague and I think intended to be such, but below I sketch an outline of issues that have been named as benefits by various actors internationally. This overview is by no means exhaustive but rather illustrative.

\begin{tabular}{|c|c|c|c|}
\hline & Health & Commercial & Scientific \\
\hline Individual level & $\begin{array}{l}\text { Designer drugs and } \\
\text { other individual } \\
\text { aspects of } \\
\text { "personalised } \\
\text { medicine" }\end{array}$ & $\begin{array}{l}\text { Profits to the } \\
\text { investors }\end{array}$ & \multirow{4}{*}{$\begin{array}{l}\text { Non-instrumental } \\
\text { knowledge: } \\
\text { development of } \\
\text { science and } \\
\text { knowledge as a } \\
\text { value in itself, } \\
\text { regardless of the } \\
\text { fact whether it is } \\
\text { useful to humans }\end{array}$} \\
\hline Communal level & $\begin{array}{l}\text { Relief to disease- } \\
\text { related populations } \\
\text { etc }\end{array}$ & & \\
\hline $\begin{array}{l}\text { National, state } \\
\text { level }\end{array}$ & $\begin{array}{l}\text { Efficient health } \\
\text { care services, } \\
\text { policy planning etc }\end{array}$ & $\begin{array}{l}\text { Development of } \\
\text { biotech and related } \\
\text { sectors, new jobs } \\
\text { etc }\end{array}$ & \\
\hline Global level & $\begin{array}{l}\text { Eradication of } \\
\text { diseases etc }\end{array}$ & & \\
\hline
\end{tabular}

The table demonstrates the all-encompassing scope of the hopes and dreams we have with respect to developments in genetic research. The question now is, what would be the basis or rationale for the sharing of these benefits? And here various, even competing justifications can be distinguished.

\section{Sharing on what basis?}

From the abovementioned international documents as well as from various other sources, I have sketched below some relevant strands of reasoning that the calls for benefit-sharing could be based on: 
1) Benefit-sharing as compensation for risk(s) taken. This aspect is currently clearly more relevant in clinical trials where risks can be rather direct and serious, especially as new medical interventions are tried out and evaluated. Human genetic research currently involves mostly giving of various samples, and risks have so far been more theoretical - discrimination based on one's genetic makeup, concerns of privacy and of psychological stress when genetic tests reveal a potential disease without the possibility for cure. Benefit-sharing in this instance would be a compensatory activity geared towards those who have taken risks that are necessary for research to take place and to possibly succeed. (Besides health risks, for example, the financial risks of investors can also be considered under this reasoning).

2) Benefit-sharing discussions in the context of genetic research are characterized by another aspect that focuses on compensatory arguments based on the notion of property. The world's agricultural sector has had the earliest experiences with this aspect of benefit-sharing. There exist numerous examples of cases where the results of the research and developing activities accomplished throughout the centuries by local communities are seized by big industry (as a rule originating from the industrialized country), and the latter has the available resources to allow it to 'cross the finish line' and capitalize alone on a certain product through patenting. ${ }^{7}$ Once the patent has been granted, the local community from a developing country has no means or resources to challenge the situation. Thus the goods are extracted from poorer countries, labelled as someone's property and often very little or nothing goes back to the communities that have originally contributed. Bioprospecting or perhaps biopiracy? Therefore one of the arguments behind benefit-sharing refers to the past and present inequalities of power and resources in the world, that are capitalized upon by big international corporations, creating and enforcing further injustice between the developing and industrialized countries. Benefit-sharing here is an attempt to change or at least alleviate this situation by putting forward essentially rectifying arguments that are based on some sort of notion of property and the utilization of that property.

The subject matter of human genetic material as property is a much debated one. This is either conceptualized as a shared property in human genome, or alternatively, as property in one's own personal genome. The UNESCO declaration on the Human Genome and Human Rights established genome as a heritage of humanity in a symbolic sense, such wording specifically not being capable of supporting legal action. In reality, the abovementioned declaration, as well as others that stress the need for benefit-sharing, (e.g. the HUGO Statement on the Principled Conduct of Genetic Research), exist side by side with others that directly contradict the ideas and principles embedded in the former (like the WTO's Trade Related Aspects of International Property Rights, the TRIPs agreement). Thus while the notion of shared property in human genome has been established symbolically, the parallel conventions detail out the private ownership rights and duties in utmost practicality, with pharmaceutical companies owning patents on human genes and cell lines.

However, private ownership does not seem to imply personal ownership. The first infamous legal case in establishing a property right in one's bodily material concluded that even if one would own the specific cells in one's body, this did not mean that the cell lines derived from it would also be owned. ${ }^{8}$ The owner(s) of the genetic data have 
not done anything to make their property valuable and therefore, at least in terms of patenting, should not have similar rights as researchers who have added value to $\mathrm{it}^{9}$ a sort of Lockean understanding of mixing one's labour with natural resources. ${ }^{10}$ David Townend has concluded that the only function that the property right in one's own genetic information can have, is that of a shield. ${ }^{11}$ That is, property right in this case allows for protection only, and not for exploitation, selling or buying. The ongoing patenting of human gene sequences allows for the property argument but mostly not on behalf of individuals or communities.

3) Compensation for fairness as a basis for benefit-sharing refers to a realization that increasingly some aspects of medicine are not as altruistic as they used to be. Certainly not all medicine can straightforwardly be equated with business but the developments in genetics have brought this characteristic to the forefront, and gradually our hopes and dreams in medicine are linked up with the rather expensive promises of genetics. The medical industry has become big business - the pharmaceutical trade sector, for example, has for a while been the most profitable in the world. ${ }^{12}$ Perhaps benefit-sharing has become such an issue because people have realized that their volunteering is not matched with altruism from the other side, and consequently compensation for fairness is required? If big profits are made, then a feeling of fairness would ask for a sharing with participants.

Historically, rewards or incentives for research participation were outlawed in order to ensure that no coercion or pressure was put on the volunteers. Much of the benefitsharing discussion, with the exception of the HUGO statement, has so far mostly been silent on that aspect, although it is clear that the promised benefits might have direct relevance to the participation decision. Presently, compensation for fairness as a moral argument seems to be the strongest basis for benefit-sharing and thus supported by various international documents. Compensation for fairness usually includes various international and social justice concerns, and here the justification for benefit-sharing is a moral one - those who have the power and are able to act in alleviating suffering have the moral obligation of doing so, based on concepts of solidarity and justice. ${ }^{13}$ But the question of who exactly is responsible for such activities is unclear. More specific examples of moral duties that are relevant here include:

- Duty not to exploit the vulnerable (Nuffield Council) ${ }^{14}$ refers to the duty to abstain from taking advantage of the unequal circumstances of power, resources and opportunities in this world, a negative duty to refrain.

- Duty to alleviate suffering (Nuffield Council) points to the necessity of providing benefits to those in need, a sort of positive requirement for those who have the power to act.

- Special moral obligations of medical enterprises. Human health is a fundamental value, a base upon which much else in life can be built. This is an idea that the HUGO ethics committee referred to when suggesting, in its statement on benefit-sharing, that companies involved in health care and medicine might have special moral obligations that other enterprises do not have. Genetic research and its applications were initially clearly situated in the sphere of medicine, suggesting that benefits should be allocated based on 
need. However, for the past decade, the investments into biomedical research have increasingly been originating from private enterprises, and the distributive principles of the business-world (like desert and merit) are increasingly influential within genetic research. From a justice point of view there is a conflict between health care and business in terms of their distributive principles. ${ }^{15}$ As in genetic research the spheres of health care and business overlap, the principles of need and desert create conflicts with both sides utilizing the arguments of justice for their own cause.

So should participants refer to charity and benevolence when discussing benefitsharing or should they feel entitled to a profit based on ownership rights and justice concerns? Whether it is compensation for risks taken, for fairness' sake or for having contributed their property for the research, entitlement to some benefits can in principle be justified. When genetic research is viewed as a for-profit activity then certainly business relationships can be applied. True, it is a special kind of business, having to do with human life and death issues. It is the very sensitivity of this particular area that causes difficulties for benefit-sharing discussions.

\section{Sharing with whom?}

An understanding that benefit-sharing can be justified through different arguments does not say much about how this framework should be applied. Traditionally, in a medical context, benefit-sharing has centred on research participants, be it individuals, families or (increasingly) communities. How is that focus on research participants justified in genetic research? The intergenerational nature of genetic information also engages other people besides those directly participating. If taking risks has been an appropriate argument for benefit-sharing among those directly involved, then genetic research might also create risks for those people who have not been participating. The content of the notion of risk is increasingly difficult to pin down where genetic information is concerned, which suggests that while risk-taking was useful for regulating benefit-sharing within traditional medical research, it might not be a suitable justification in many instances of genetic research.

The property argument for benefit-sharing has been most successfully applied in cases of communities and nations (usually having to do with non-human genetic resources). Possibly some specific cases of monogenetic diseases can also rely on this argument, at least implicitly. For example, disease-advocacy groups in the US have in some instances been successful in negotiating for direct benefits, as their contributions are easier to prove. ${ }^{16}$ But their argument for sharing can also be based on the notion of fairness.

Fairness and various justice-related concepts are notoriously difficult to agree on, and the complex nature of genetic information hampers the successful application of this concept in benefit-sharing further. Whose concerns are to be taken as relevant? In small-scale clinical drug trials this is easier to assess compared to large populationbased genetic databases, where significant social concerns might arise. ${ }^{17}$ Subsequently I would draw attention to a very close dependency between how we justify benefit-sharing and who those are to be shared with. This works both ways whether we start with abstract justification that will determine the circle of those to 
whom it applies; or whether we are concerned with certain individuals, communities, peoples etc., and therefore argue for a benefit-sharing principle that would take their interests into account. For example, when we consider the genome to be a common property of humanity, the sharing should clearly be done among all human beings. An understanding that these aspects of benefit-sharing are closely linked is important to keep in mind. Some of the uncertainties and doubts that have accompanied the benefit-sharing discussion in human genetic research might have to do with the fact that some justificatory arguments are not efficient in including the interests of relevant populations. For example, benefit-sharing arguments based on international injustice might not fit so well with the public concerns regarding research conducted in industrialized countries.

By drawing on parallels with clinical research I have so far focused mostly on benefitsharing among research participants, but other possibilities have been argued for. In recent years, the discussions regarding benefit-sharing in human genetic research have increasingly stressed that everyone should benefit, and that the entire humankind should be involved in the sharing. ${ }^{18}$ Here the concept is employed to fight the activities of patenting and commercialization that monopolize and limit access to the results of genetic research. The right to benefit from genetic research would then be based on a fact that humans share $99 \%$ of the genome. To quote Ortúzar: " there is no reason to confer benefit exclusively on the population which is the subject of the research /.../ all benefit derived from genetic research on populations should be available to anyone in need of the health improvement offered by it." 19 Indeed, benefits to participants can be seen as unfair from the point of view of universal benefit-sharing.

I believe it is necessary to distinguish two different aspects in the benefit-sharing framework. At least a differentiation needs to be made between the universal list of benefits mentioned in the table above - that describes the entire positive potential of the genetic enterprise - and a specific benefit-sharing framework directed towards those who directly participate in research. I believe these two issues need to be kept separately if we still want to make use of the sharing framework. By differentiating between universal and specific sharing, much confusion is avoided because many benefit-sharing arguments function only in specific context, whereas others have relevance in universal context.

\section{Limitations of universal benefit-sharing framework}

Calls for universal benefit-sharing have been based on concerns for justice in an international genetic research situation. The agricultural background to benefitsharing can possibly explain some tendencies that have characterized this discussion within human genetics. Namely, the presupposition that in genetic research (in parallel with agriculture, and say, mining) there exist certain clear-cut and tangible benefits and/or resources that can be easily assessed, accessed and distributed. The assumption that benefits are out there, almost graspable, disregards the social context of human genetics and the controversial nature, as well as the mere potentiality, of many benefits. Because of the amount of hype that has surrounded human genetics (in comparison to plant and animal genetics), many overoptimistic visions as well as nightmares have become regarded as rather realistic benefits and burdens. 
Benefit-sharing seems to be on the one hand fuelled by feelings of injustice emerging from the inequalities of power between the global medical and pharmaceutical industry and the resource-rich less developed countries; on the other hand the scene has been much influenced by the often over-hyped visions of grand future developments. I think that benefit-sharing discussion in genetics would not have gained such prominent status if it was not for the previously existing global injustices that are not directly linked to genetic research. I refer to a larger background of current world inequalities in terms of opportunities and resources that stem from various sources, be it inherited from colonization experience or the international establishment of market-oriented liberal capitalism that favours certain prominent players and regulations in the ordering of our world. The dissatisfaction that forms the basis for a universal benefit-sharing requirement is larger than only genetic research allows for. It is clear that benefit-sharing is hoped somewhat to address this dissatisfaction, despite the fact that much of it stems from areas not connected to genetic research. To my mind the problem is that a benefit-sharing framework is not able to respond adequately to those concerns that surface from this larger background of injustice issues. Genetics is not only a health issue, and even health itself does not contain the various aspects of human existence that are relevant from the justice point of view.

Different political and economic instruments can be and should be utilized once there is political will to seriously deal with existing injustices and inequalities in the world. But I fear that benefit-sharing as a framework originating from research lacks coherent strength, and might be simply inadequate for enforcing the claims that are currently made within it to alleviate the widening gap between the industrialized and developing countries. If the patenting system is unfair, then benefit-sharing is not able to challenge that unfairness sufficiently, but rather, policy changes are required. Benefit-sharing should be used to its maximum potential, including, if possible, the sharing of benefits to those not directly involved, but that will not even be a remotely adequate solution for the international justice predicament. Below I have attempted to draw out some concerns that ground my scepticism regarding the inadequacy of a benefit-sharing framework in this universal-benefit-for-humanity context.

Benefits from genetic research, despite being potentially very widely applicable and relevant to human health, will only be capable of addressing a limited cluster of health care issues. Applications based on traditional (meaning non-genetic) medicine, improvements in hygiene and nutrition are still more useful in helping the populations of developing countries to achieve better health and quality of life. Currently, around 800 million people, or $18 \%$ of the world's population go hungry every day and suffer the related consequences to their health; 1.1 billion do not have access to safe water. ${ }^{20}$ Thus, even very generous redistributive actions resulting from genetic research or new medical research will not have the effects that are sorely needed and hoped for in the international situation. It is the fair provision of most basic medicine that would benefit the populations of developing countries. This of course raises the question whether shared benefits would necessarily have to be related to, or result from, genetic research. Possibly benefit-sharing in genetic research could allow for anything to be shared, as long as it is defined as a benefit by a substantial amount of stakeholders. On the other hand, this only illustrates the concern I alluded to above namely that benefits distributed via genetic research (whether they themselves are 
"genetic" or not) are not in any way a sufficient measure to alleviate the problems where genetic research forms only a minor part, or indeed, is only a symptom and not a cause. And it should not be forgotten that many of these hoped-for benefits currently constitute little more than heavily hyped visions of the contingent human enterprise of science.

Secondly, much of the discussion in benefit-sharing discourse is ambiguous and incoherent, as it utilizes several arguments that exclude each other. Thus it can be easily dismissed or 'dealt with' through dispersing with a few coloured ribbons and glass-beads, so to speak. After all, fairness and justice are very difficult to pin down and agree on. Many would refer to a certain 'gut-feeling' that in principle benefits are due in return for a contribution, but in the complexities of genetic research these are in many cases very hard to establish. Monogenetic diseases (where contributions would perhaps be easier to distinguish) are very rare, and most of the genetics-related expectations are linked to discoveries in the common complex diseases. Research on these diseases, especially because they are strongly linked to environmental factors, will necessarily involve very many participants and samples. Involvement of hundreds and thousands would be needed even to start contemplating any relations between a disease outbreak, DNA and environmental factors. This also means that tracking someone's individual contribution would be unthinkable. The quality here really comes with quantity.

It is difficult to fathom that universal benefit-sharing based on the universal property argument is realizable. Presently the symbolic heritage of humanity is privatized with increasing speed to companies, research agencies and others. Even if appropriate laws were changed, it is open to discussion what entitlements this would create as regards benefits. It could be argued that no-one can be excluded from enjoying benefits (and this is already demanded now - see the quotes from the beginning of the article), but it is much more complicated to argue for anything more substantial, at least based on the notion of property. The notion of global public goods or the human rights discourse has a better chance in distributing the needed resources. Compensation for risk cannot be highly relevant in universal sharing, as risks in medical projects traditionally involve limited number of participants. Even if communities or populations are engaged (for example in setting up population based genetic databases), universal sharing is still not relevant within this risk-based reasoning. Compensation for fairness is too vague, at least within genetic research, as its potential is bound by the specific research protocols and by particular issues under investigation. It lacks coherence and complexity to be successful outside of these limits to tackle the real causes for rallying behind benefit-sharing. ${ }^{21}$

My final reason for scepticism regarding the universal applicability of benefit-sharing framework in genetics is a pragmatic one. If the currently most powerful universal discourse - that of human rights - is only slowly improving the international situation regarding human health and quality of life satisfactorily, then the rather specific line of benefit-sharing thought originating from the uneasy mixture of research and business activities, does not look very promising. However, this is a conclusion regarding universal benefit-sharing and not the framework for specific research projects. 
Ted Schrecker has insisted that any "responsible ethical analysis must not regard crucial background elements of the social and economic context /.../ as too big to change" and has urged the linking of benefit-sharing discussion with the critique of "market fundamentalism". ${ }^{22}$ What I hope to have done is precisely the investigation of this link. My conclusions however state the theoretical and practical inadequacy of the benefit-sharing concept to deal with these large scale issues.

This does not mean that the battle for a more just world is lost - it simply needs more suitable and more powerful "weapons". Unfailing and consistent political pressure on the enforcement of so-called second generation or socio-economic rights is important in the context of health care. On the other hand, the implementation of these rights is very much dependent on the available resources of countries. Therefore simply pressure on rights discourse is inadequate without the inclusion of more systematic critical approaches to tackling the global structural inequalities. For example, the way international copyright and trade regulations function in reproducing and enforcing the age old disparities between the industrialized and developing countries should be challenged. These rules are by no means neutral or even fair. ${ }^{23}$ I believe that these approaches are better equipped to address the concerns that have been behind much of the engagement for benefit-sharing of the technological and biomedical developments on a more universal level. It is the investigation and application of these frameworks that have a better chance in dealing with global inequalities, both because they are better grounded theoretically and because their implications are much wider than the limited areas of benefit-sharing of genetic or even biomedical research results. This research promises, and hopefully will deliver, a lot, but the improvement in the health and condition of humankind cannot be achieved with the focus on a rather ambiguous concept of universal benefit-sharing.

\section{Acknowledgements}

I am most grateful to Margit Sutrop, Ruth Chadwick, Sue Weldon, Graham Lewis, Andrew Webster and two anonymous reviewers for their help and insights with this article. All the views presented as well as the mistakes remain my own. The article has benefited from the financial support of the projects The Ethical, Legal and Social Aspects of Human Genetic Databases: A European Comparison, financed between 2002-2004 by the European Commission's Fifth Framework Programme (contract number QLG6-CT-2001-00062) and the Estonian Science Foundation grant Ethical Aspects of Genetic Databases and New Technologies (no. 6099).

\footnotetext{
${ }^{1}$ P. A. King. 1992. The Past as Prologue: Race, Class, and Gene Discrimination. In Gene Mapping. Using Law and Ethics as Guides, G. J. Annas and S. Elias, eds. New York. Oxford University Press :95.; World Health Organization. 2002. "Genomics and World Health". Geneva.

2 This definition and my entire article has its main focus on human genetic research, leaving aside agriculture, forestry, animal husbandry and many other areas where genetic research is ongoing.

3 As a side-remark, I'd like to note that benefit-sharing discussion in genetics is such a prominent topic first and foremost because the potential benefits are envisioned rather significant and pretentious in both financial and scientific terms, and also that many of the risks or burdens taken are rather serious as
} 
well. Most likely, more altruistic approaches and less benefit calculating characterize co-operations of less extravagant promises.

${ }^{4}$ T. Airaksinen. Why Do Inequalities in Health Exist? Acta Philosophica Fennica. Justice, Charity, and the Welfare State: Moral and Social Dimensions 2001; 68.

5 M. Douglas, A. Wildavsky 1982. Risk and Culture. An Essay on the Selection of Technical and Environmental Dangers. Berkeley, CA. Univerisity of California Press. P.8.

${ }^{6}$ I do not attempt to clarify this situation in terms of possible causes for such behaviour, I have simply used it here to illustrate the point about the existence of various understandings of 'benefits' regardless of how we can or cannot explain them.

7 Some classic examples from agriculture are presented by David Magnus. International Agricultural Perspectives. Conference „Toward an understanding of benefit-sharing“, Philadelphia, March 3, 2003. http://www.bioethics.upenn.edu/prog/benefit/pdf/Magnus_David.pdf (accessed 24.05.2005)

${ }^{8}$ On Moore v. Regents of University of California see C. A.Erin. 1994. Who Owns Mo? Using historical entitlement theory to decide the ownership of human derived cell lines. In Ethics and Biotechnology, A. Dyson and J. Harris, eds. London, Routledge.

9 R. Chadwick, K. Berg. Solidarity and equity: new ethical frameworks for genetic databases. Nature Review Genetics 2001; 2: 320.

${ }^{10}$ Locke of course had an important clause to the property-creation process, namely this was only allowed when ,there was still enough and as good left” („An Essay”, ch.5, paragraph 33). It is questionable whether patenting gene functions and sequences does leave enough for others.

11 D. Townend. 2003. Who owns genetic information? In Society and Genetic Information, Codes and Laws in the Genetic Era, J. Sandor ,ed.Budapest-NY. Central European University Press: 142.

${ }^{12}$ HUGO Ethics Committee. Genetic Benefit-sharing. Science 2000; 290: 49.

13 See for example Chadwick,Berg, op.cit.note 10.

14 Nuffield Council on Bioethics. 2002. The ethics of research related to healthcare in developing countries. Available at http://www.nuffieldbioethics.org/publications/pp 0000000013.asp (accessed 24.05.2005)

15 R. Chadwick, A. Hedgecoe. 1998. Commercialisation of the human genome. In A Companion to Genethics, J. Burley, J. Harris, eds. Oxford. Blackwell.

16 Some of the best known examples are PXE International and Alpha-One Foundation.

17 For some such concerns raised by the Estonian Genome Project see M.Sutrop, K.Simm. The Estonian health care system and the genetic database project: from limited resources to big hopes. Cambridge Quarterly on Health Care Ethics 2004; 13, 3: 254-262.

${ }^{18}$ See for example, L. Mansur. Gene Discovery, Ownership and Access for Developing Countries in the Era of Molecular Genetics. Electronic Journal of Biotechnology 2002; 5, 1. (http://www.ejbiotechnology.info/content/vol5/issue1/issues/05/); M. G. de Ortứzar. 2003. Towards a Universal Definition of 'Benefit-Sharing. In Populations and Genetics: Legal and Socio-Ethical Perspectives, B.M.Knoppers, ed. Leiden. Martinus Nijhoff. ; Ted Schrecker. 2003. Benefit-Sharing in the New Genomic Marketplace: Expanding the Ethical Frame of Reference. In B.M.Knoppers, ed.

19 Ortúzzar op.cit.note 18, p.478.

${ }^{20}$ United Nations Human Development Report. 2003. http://www.undp.org/hdr2003/

${ }^{21}$ On the limited global relevance of some genetic benefits see for example R. Chadwick, S. Wilson. Genomic Databases as Global Public Goods. Res Publica 2004; 10.. P.123-134.

${ }^{22}$ Schrecker, op.cit.note 18, pp.406-407.

23 See for example T. Pogge. 2002. World Poverty and Human Rights. Cambridge.Polity Press. 